\title{
Efeitos da precipitação pluviométrica sobre a produção agrícola nos municípios de Belmonte e Ipiaú, estado da Bahia, Brasil
}

\begin{abstract}
Effects of pluviometric precipitation on agricultural production in the municipalities of Belmonte and Ipiaú, Bahia states, Brazil
\end{abstract}

Efectos de la precipitación pluviométrica sobre la producción agrícola en los municipios de Belmonte y Ipiaú, Estado de Bahia, Brasil

Paulo César Bahia de Aguiar
Nelma Lima Bruno
Mônica de Moura Pires
Christiana Cabicieri Profice
4
Universidade Estadual de Santa Cruz - UESC, Ilhéus, Bahia
Josiclêda Domiciano Galvíncio
Universidade Federal de Pernambuco, Recife, Pernambuco

1 Doutorando em Desenvolvimento e Meio Ambiente pela Universidade Estadual de Santa Cruz -- UESC, Ilhéus, Bahia , Brasil. Bolsista da Fundação de Amparo a Pesquisa do Estado da Bahia - FAPESB. E-mail. prof.pauloaguiar@bol.com.br

2 Doutoranda em Desenvolvimento e Meio Ambiente pela UESC, Ilhéus, Bahia, Brasil . Bolsista da Coordenação de Aperfeiçoamento de Pessoal de Nível Superior - CAPES. E-mail: nelmalima06@hotmail.com.

3 Doutora em Economia Rural. Professora Plena do Departamento de Ciências Econômicas da UESC. Email:mpires@uesc.br

4 Doutora em Psicologia Social pela Universidade Federal do Rio Grande do Norte. Professora Titular do Departamento de Filosofia e Ciências Humanas da UESC. E-mail: ccprofice@uesc.br

5 Doutora em Recursos Naturais pela Universidade Federal de Campina Grande, Paraíba. Professora Associada I da Universidade Federal de Pernambuco - UFPE. E-mail: josicleda@gmail.com 


\title{
Resumo
}

Este artigo tem como objetivo comparar e analisar as influências dos padrões de precipitação pluviométrica, em dois períodos distintos de normais climatológicas (médias do acumulado mensal), sobre a produção agrícola dos municípios de Belmonte e Ipiaú, Bahia. Para isso, fez-se levantamento de dados secundários de natureza socioeconômica para caracterização socioeconômica dos municípios; séries históricas de dados pluviométricos, relativas aos períodos de 1956 a 1987, e 1996 a 2017 (Belmonte) e 1950 a 1979 e 1980 a 2008 (Ipiaú). Com isso, fez-se comparação e análise dos dois períodos e a evolução dos principais produtos agrícolas dos municípios, a fim de identificar as influências dos padrões de chuva na produção agrícola. Verificou-se que em Belmonte, na maior parte do período entre os anos de 2004 a 2015, houve diminuição no perfil total de chuva, e os principais produtos agrícolas apresentaram produção crescente ou estável. Em Ipiaú, observou-se que os picos de chuva dentro do total pluviométrico foram maiores no primeiro período analisado (1950 a 1979); e que excessos de chuva influenciaram negativamente alguns cultivos, sobretudo a produção de olerícolas cultivadas por pequenos e médios agricultores. Pode-se inferir que para os períodos analisados o padrão de pluviosidade pouco se alterou, e as mudanças observadas não afetaram a distribuição de chuvas ao longo do ano, mantendo-se relativamente bem distribuída.

Palavras-chave: dinâmica climatológica; Agricultura; Normais climatológicas.

\begin{abstract}
The objective of this article is to compare and analyze the influence of rainfall patterns, in two distinct climatological normal periods (average monthly accumulation), on the agricultural production of the municipalities of Belmonte and Ipiaú, Bahia. For this, secondary socioeconomic data were collected for the socioeconomic characterization of the municipalities; historical series of rainfall data for the periods 1956 to 1987 and 1996 to 2017 (Belmonte) and 1950 to 1979 and 1980 to 2008 (Ipiaú). This led to the comparison and analysis of the two periods and the evolution of the main agricultural products of the municipalities, in order to identify the influence of rainfall patterns on agricultural production. It was verified that in Belmonte, during the majority of the period between the years 2004 to 2015, there was a decrease in the total rainfall profile, and the main agricultural products presented increasing or stable production. In Ipiaú, it was observed that rainfall peaks within the rainfall total were higher in the first period analyzed (1950 to 1979); and that excessive rainfall has negatively influenced some crops, especially the production of small and medium-sized farms. It can be inferred that for the periods analyzed, the rainfall pattern did not change much, and the changes observed did not affect the rainfall distribution throughout the year, remaining relatively well distributed.
\end{abstract}

Keywords: Climatological dynamics; Agriculture; Climatic norms.

\section{Resumen}

Este artículo tiene como objetivo comparar y analizar la influencia de los patrones de precipitación pluviométrica, en dos períodos distintos de normales climatológicas (medias del acumulado mensual), sobre la producción agrícola de los municipios de Belmonte e Ipiaú, Bahía. Para ${ }_{\text {ello, }}$ se hizo el levantamiento de datos secundarios de naturaleza socioeconómica para la caracterización socioeconómica de los municipios; las series históricas de datos pluviométricos, relativas a los períodos de 1956 a 1987, y 1996 a 2017 (Belmonte) y 1950 a 1979 y 1980 a 2008 (Ipiaú). Con ello, se hizo una comparación y análisis de los dos períodos y la evolución de los principales productos agrícolas de los municipios, a fin de identificar las influencias de los patrones de lluvia en la producción agrícola. Se constató que en Belmonte, en la mayor parte del período entre los años 2004 a 2015, 
hubo disminución en el perfil total de lluvia, y los principales productos agrícolas presentaron una producción creciente o estable. En Ipiaú, se observó que los picos de lluvia dentro del total pluviométrico fueron mayores en el primer período analizado (1950 a 1979); y que excesos de lluvia, influenciaron negativamente algunos cultivos, sobre todo la producción de olerícolas cultivadas por pequeños y medianos agricultores. Se puede inferir, que para los períodos analizados, el patrón de pluviosidad poco se alteró, y los cambios observados no afectaron la distribución de lluvias a lo largo del año, manteniéndose relativamente bien distribuida.

Palabras clave: Dinámica climatológica; Agricultura; Normas climatológicas.

\section{Introdução}

O clima se constitui em um elemento de fundamental importância para a sociedade humana, dentro da dinâmica da natureza, pois influencia diretamente o modo de vida humano e propicia condições fundamentais à sobrevivência das espécies.

Segundo Calazans, Levy e Moreau (2005), diferente do tempo meteorológico, que é uma experiência diária, ou seja, o estado instantâneo da atmosfera [numa dada porção de tempo e em determinado lugar], o clima é uma generalização ou integração das condições do tempo para certo período [normalmente um espaço de tempo mínimo de 30 anos], em uma determinada área. Esses autores pontuam que conceitos como elementos climáticos e fatores climáticos são fundamentais no entendimento sobre o clima. Por elementos climáticos entende-se um conjunto de grandezas que quantificam o clima, tais como a insolação, irradiância, temperatura e umidade do ar, nebulosidade, altura pluviométrica, velocidade e direção do vento, pressão atmosférica, evaporação e precipitações; já por fatores climáticos entendem-se os agentes que condicionam o clima, nas diferentes escalas espaciais.

Os estudos de climatologia há décadas vêm ganhando importância tanto no contexto internacional quanto nacional. Essa importância se deve, sobretudo, às transformações que vem ocorrendo na dinâmica climática global, havendo alteração na dinâmica climatológica nos diferentes lugares, em muitos casos de forma acentuada, refletindo diretamente na vida das pessoas.

Algumas linhas de estudo apontam que o principal fator que tem levado a essas profundas modificações na dinâmica climática global tem sido as ações antrópicas, fruto do estilo de vida explorador da natureza e consumista da sociedade capitalista hodierna, que vem provocando degradação da natureza em escala e ritmo alarmantes. Por outro lado, há linhas 
de estudo que apontam que as transformações que vem se sucedendo na dinâmica climática global é fruto da dinâmica da própria natureza, sem que as ações antrópicas tenham significância nesse processo.

Independente dos pontos de vista, nas últimas décadas os diferentes problemas associados às mudanças climáticas se intensificaram. Segundo Angelocci e Sentelhas (2010, p. 1), mudanças climáticas "designa uma tendência de alteração estatística significativa da média de um elemento climatológico ou de sua variabilidade em períodos de tempo mais extensos, como décadas ou séculos", e, conforme apontam Souza e Azevedo (2012), após a publicação do $4^{\circ}$ Relatório do IPCC (2007), passou a ser considerado, mais enfaticamente, resultado do aquecimento global.

Dentre os problemas associados ao aquecimento global e às mudanças climáticas, ou mesmo associado e potencializado por outros fatores de ordem natural, podem se mencionar os desastres naturais associados a enchentes, deslizamentos de encostas por excesso de chuva e retirada da cobertura vegetal, excessos de chuva em alguns lugares e períodos, e sua escassez em outros, terremotos, maremotos e furacões, dentre outros problemas que podem levar à perda de vidas humanas, a migrações forçadas, à ocorrência de refugiados ambientais, a perdas de lavouras e de efetivos na pecuária, e elevação no número de algumas doenças (Gouveia et al, 2017). Diversos estudos têm sido desenvolvidos voltados à compreensão das consequências das mudanças climáticas para os diferentes lugares, seu monitoramento e projeção de futuros impactos e meios de adaptação, servindo de subsídios à compreensão desse processo (Conti, 2005; Moraes et al., 2005; Santos, 2018; Piao et al., 2010; Barbieri, 2011; Souza e Azevedo, 2012; Kirsch e Schneider, 2016; Salamanca et al., 2017).

Segundo Souza e Azevedo (2012), em escala local ou regional, observações de registros climáticos de longo prazo são de importância substancial para a identificação das tendências climáticas e as suas potenciais causas, pois os impactos das oscilações climáticas na sociedade normalmente estão associados aos eventos extremos de precipitação ou secas, se refletindo na agricultura, nos recursos hídricos, na saúde e sobre o meio ambiente.

Desenvolver estudos voltados à compreensão da dinâmica climática local, a partir de séries históricas "normais climatológicas" é fundamental para a identificação da tendência climática desses lugares e a possível predição de determinadas condições. Tais observações de uma série 
padronizada, por exemplo, para um período de 30 anos, são de grande valia, e quando dentro desse período se trabalha com uma média, tem-se uma normal climatológica, que se constituiu em um indicador das condições susceptíveis de ocorrerem em dada região (Oliveira e Veccia, 2011). Portanto, estudar a dinâmica climatológica na escala local por meio de séries históricas padronizadas, como, por exemplo, na escala de um município, é salutar tanto para compreender a tendência climatológica local e sua influência em outras variáveis de importância para os grupos humanos ali localizados, a exemplo da produção agrícola, como para contribuir com a compreensão da dinâmica mais ampla do clima.

Nesse contexto, o presente estudo se propõe contribuir para ampliar as discussões a respeito da dinâmica climática e a sua relação com a produção agrícola, em escala local, a partir do estudo de dois municípios sul baiano, especialmente frente a atual conjuntura de transformações do clima, as quais geram necessidades de adaptações do ser humano e da natureza.

Sendo assim, a problemática de pesquisa levada em consideração neste artigo está relacionada às seguintes questões: Qual foi o perfil de evolução das normais climatológicas do município de Belmonte, Bahia, nos períodos compreendidos entre os anos de 1956 a 1987, e 1996 a 2016, e das normais climatológicas do município de Ipiaú, Bahia, nos períodos compreendidos entre os anos de 1950 a 1979, e 1980 a 2008?; Quais as possíveis influências dos padrões de precipitação pluviométrica recente na produção agrícola desses municípios? Portanto, este artigo tem como objetivo comparar e analisar dois períodos de normais climatológicas (médias do acumulado mensal) do município de Belmonte, e do município de Ipiaú, Bahia, e as possíveis influências dos padrões de precipitação pluviométrica recente na produção agrícola desses municípios.

A escolha desses dois municípios para serem estudados se deve às suas localizações geográficas: o município de Ipiaú está mais ao norte na microrregião Ilhéus-Itabuna, em uma posição interiorizada no continente; enquanto o município de Belmonte se encontra no limite sul da citada microrregião e em uma posição litorânea. Essas localizações distintas de cada município, associado às suas características fisiográficas específicas, permitirá ter certa noção se esses fatores têm influenciado para grandes variações nas normais climatológicas entre os municípios, ou se há semelhanças entre esses municípios no aspecto climatológico mesmo a despeito de suas localizações geográficas em pontos distintos do território. 


\section{Material e Métodos}

\section{Áreas de Estudo}

O município de Belmonte possui uma extensão territorial de 1.970,14 $\mathrm{km}^{2}$, está localizado na microrregião Ilhéus-Itabuna (composta de $41 \mathrm{mu}-$ nicípios), conforme regionalização do IBGE (Figura 1), e é abrangido pelo Bioma Mata Atlântica. Na atual divisão regional do Brasil, estabelecida pelo IBGE em 2017, Belmonte está incluso na Região Geográfica Intermediária Ilhéus-Itabuna, a qual tem sob sua influência 51 municípios, e é composta pelas Regiões Geográficas Diretas (Imediatas) de Ilhéus-Itabuna, Teixeira de Freitas, Eunápolis-Porto Seguro e de Camacan. No âmbito do Governo do Estado da Bahia, o qual a partir de 2007 estabeleceu uma regionalização para o estado em 26 Territórios de Identidade, esse município está incluso no Território de Identidade Costa do Descobrimento, abrangendo áreas pioneiras da colonização nacional.

Por sua vez, o município de Ipiaú possui uma extensão territorial de $287,5 \mathrm{~km}^{2}$, equivalendo a $0,05 \%$ da área total do estado; também está localizado na microrregião Ilhéus-Itabuna, e é abrangido pelo Bioma Mata Atlântica. Na divisão regional do IBGE de 2017, Ipiaú se encontra na Região Geográfica Intermediária Ilhéus-Itabuna. E, na regionalização promovida pelo estado da Bahia, encontra-se situado no Território de Identidade Médio Rio das Contas.

O indicador Índice de Desenvolvimento Humano Municipal de Belmonte, do ano de 2010, colocou esse município na condição de Médio Desenvolvimento Humano, mesma condição do estado da Bahia; já o Brasil se encontrava na condição de Alto Desenvolvimento Humano. No referido município a variável que se sobressaía era a Longevidade (condição alta); na sequência vinha a Renda (condição média); e, por fim, a Educação, que ainda se encontrava em uma condição de baixo desenvolvimento (Tabela 1). Interessante se faz mencionar que tanto na escala do município de Belmonte, quanto na do Estado da Bahia ou mesmo a do Brasil, a variável Longevidade apresentava um Alto Desenvolvimento; já a Renda apresentava Médio Desenvolvimento, tanto no município quanto no estado, e Alto Desenvolvimento em nível de Brasil; e a variável Educação apresentava Baixo Desenvolvimento no município, mas Médio Desenvolvimento tanto em nível estadual quanto nacional - sendo essa a variável mais baixa nas três esferas, implicando dizer que mesmo tendo ocorrido relativas 


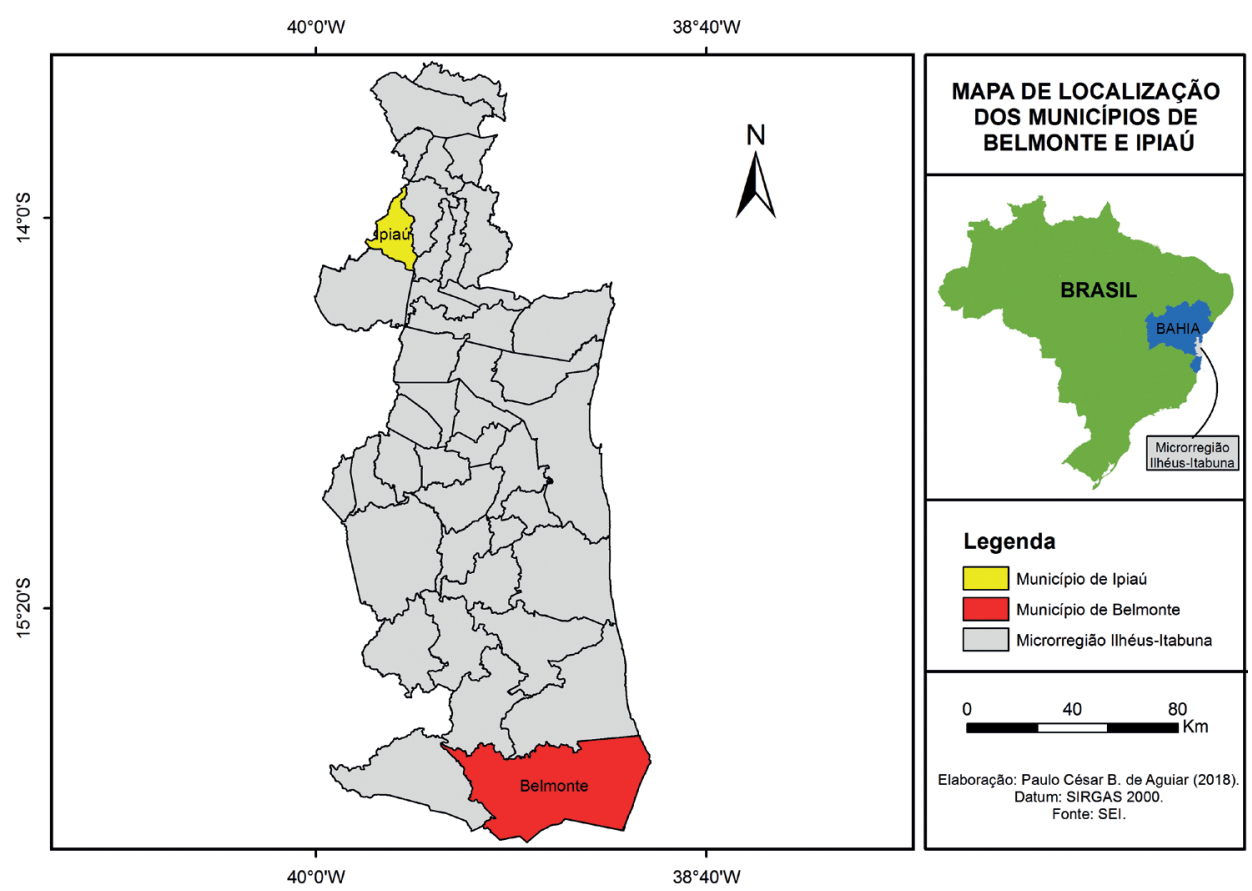

Figura 1. Localização de Belmonte e Ipiaú na microrregião IlhéusItabuna, da microrregião Ilhéus-Itabuna no estado da Bahia, e da Bahia no Brasil.

Elaboração própria: Aguiar, Paulo César B. de., a partir de base cartográfica da SEI.

melhoras no âmbito da gestão e da efetivação do processo educativo, e, por conseguinte, nos seus resultados, ainda a educação nacional é uma problemática que requer a adoção de medidas eficazes de aprimoramento.

No aspecto sanitário, 88,68\% dos domicílios do município considerado possuíam água encanada; $92,89 \%$ dos domicílios eram atendidos pelo sistema de coleta de lixo público; e $91,77 \%$ das residências possuíam energia elétrica (PNUD, 2013) - o que dá subsídio à população ao acesso a um conjunto de eletrodomésticos, considerados bens essenciais.

O município de Ipiaú, no ano de 2010, também apresentou um médio IDH-M, sendo que também para esse município a variável que se sobressaiu foi a Longevidade, que apresentou um Alto Desenvolvimento Humano, e a Educação foi a variável com menor desempenho, embora representando um Médio Desenvolvimento Humano. 
Nos aspectos sanitários, 93,49\% dos domicílios do município de Ipiaú possuíam água encanada; $99,05 \%$ das residências possuíam energia elétrica; e 97,28\% dos domicílios eram atendidos pelo sistema de coleta de lixo público (PNUD, 2013).

Tabela 1. Ìndice de Desenvolvimento Humano do município de

Belmonte e de Ipiaú, do Estado da Bahia e do Brasil, em 2010.

\begin{tabular}{|c|l|c|c|c|c|}
\hline \multirow{2}{*}{ Ano } & Indicador & $\begin{array}{c}\text { Município de } \\
\text { Belmonte }\end{array}$ & $\begin{array}{c}\text { Município de } \\
\text { Ipiaú }\end{array}$ & $\begin{array}{c}\text { Estado da } \\
\text { bahia }\end{array}$ & Brasil \\
\hline \multirow{3}{*}{2010} & IDH & $\mathbf{0 , 5 9 8}$ & $\mathbf{0 , 6 7 0}$ & $\mathbf{0 , 6 6 0}$ & $\mathbf{0 , 7 2 7}$ \\
\cline { 2 - 6 } & Educação & 0,480 & 0,551 & 0,555 & 0,637 \\
\cline { 2 - 6 } & Longevidade & 0,771 & 0,796 & 0,783 & 0,816 \\
\cline { 2 - 6 } & Renda & 0,577 & 0,687 & 0,663 & 0,739 \\
\hline
\end{tabular}

Fonte: PNUD - Programa das Nações Unidas para o Desenvolvimento. Atlas de Desenvolvimento Humano no Brasil, 2013.

Elaboração própria: Aguiar, Paulo César B. de.

\section{Metodologia}

Como metodologia, fez-se levantamento de dados secundários de natureza socioeconômica do município de Belmonte, de Ipiaú e da microrregião Ilhéus-Itabuna junto a instituições governamentais de planejamento, os quais foram tratados e representados por meio de tabelas sobre os municípios (tabelas de população, IDEB, IDH-M e PIB-M). Ainda foi construído mapa de localização dos municípios, no software ArcGis10.1. As tabelas e mapa possibilitaram com que fosse feita breve caracterização socioeconômica dos municípios em estudo.

Fez-se ainda levantamento de dados pluviométricos na página do Hidroweb, de série histórica relativa aos períodos de 1956 a 1987, e 1996 a 2016 para o município de Belmonte; e de 1950 a 1979, e 1980 a 2008 para o município de Ipiaú - (com ausência de alguns anos para ambos os municípios, em razão dos dados disponíveis). Esses dados foram tratados e representados na forma de gráficos e tabelas. Os gráficos se referem às normais climatológicas dos dois períodos considerados para cada município, ou seja, média mensal acumulada, em milímetros, e aos desvios relativos. A fórmula para cálculo da média do acumulado mensal (normais climatológicas) foi: somatório de todos os janeiros do período e a sua respectiva 
média; e o mesmo procedimento para os outros meses, até dezembro. Para cálculo do desvio relativo, primeiramente teve-se que calcular o desvio absoluto. A fórmula para calcular o desvio absoluto foi: total mensal de determinado mês menos a média do acumulado mensal representativa do mesmo mês; isso para todos os meses. Já a fórmula para cálculo do desvio relativo foi: o desvio absoluto de determinado mês divido pela média do acumulado mensal representativa do mesmo mês multiplicado por cem. Foi ainda construído gráfico de total anual de chuvas dos dois períodos, e construído um mapa de identificação da zona climática em que os municípios se encontram e das zonas de umidade, no ArcGis 10.1. Os gráficos, mapa e tabelas possibilitaram com que se fizesse a analise e comparação dos dois períodos de normais climatológicas (médias do acumulado mensal). As séries históricas dos períodos de dados diários de chuva têm sido um instrumento em potencial para levantar informações pretéritas e atuais para realizar correlações com eventos climáticos naturais ou antrópicos, e também divulgar projeções futuras. Nos últimos anos tem crescido o número de trabalhos envolvendo análise de séries históricas de elementos meteorológicos, devido ao aumento no interesse em responder a perguntas debatidas no meio científico, como, por exemplo, se o clima terrestre está mudando e de que forma essa mudança tem influenciado a agricultura.

Por fim, construiu-se uma tabela com a evolução da produção dos principais produtos agrícolas do município de Belmonte em anos recentes, e uma para o município de Ipiaú, a partir da Pesquisa Agrícola Municipal, associados aos dados de precipitação pluviométrica anual, os quais possibilitaram com que se identificassem as possíveis influências dos padrões de precipitação pluviométrica recente na produção agrícola.

\section{Dinâmica Climatológica em Belmonte e Ipiaù}

O município de Belmonte, segundo divisão do território nacional em Zonas Climáticas, pelo IBGE, ou unidades climáticas brasileiras, encontra-se situado na Zona Tropical Nordeste Oriental (Figura 2). No que se refere à distribuição de umidade, o território desse município se encontra predominantemente nas faixas sem seca e subseca. Sua temperatura média é de $24^{\circ} \mathrm{C}$ (Nascimento; Dominguez, 2010).

Conforme classificação de Thornthwaite \& Matther (1955, apud SEI, 1998), o clima onde se encontra o referido município é o úmido, e úmido a 
subúmido; e, segundo a classificação de Koppen, o clima que abrange esse município é o de característica geral quente e úmido, com particularidades de regime de chuva sempre úmido (Af).

Em relação ao município de Ipiaú, segundo a classificação do IBGE em Zonas Climáticas ou unidades climáticas brasileiras, esse município encontra-se situado na Zona Tropical Brasil Central, que abrange quase todo o território do estado da Bahia (Figura 2).

Segundo a classificação de Koppen, o clima predominante nesse município é o do tipo Tropical de Monção (Am), o qual é um clima de transição entre o tropical chuvoso de floresta/quente e úmido durante o ano todo (Af), o quente e temperado (As) e o tropical típico, com uma estação úmida no verão e outra seca no inverno (Aw) - o primeiro com estação de chuvas concentradas no outono/inverno, e o segundo, com período de chuvas concentrado na primavera/verão. Koppen ainda considera que a faixa de transição climática em estudo (Am) apresenta estação seca pouco pronunciada, compensada pelos totais anuais elevados.

As normais climatológicas do município de Belmonte para a série histórica de 1956 a 1987 (média do acumulado mensal de precipitação pluviométrica em milímetros - $\mathrm{mm}$ ) permitem observar um regime de chuvas bem distribuído ao longo dos meses, com as maiores ocorrências em março (fim do verão), abril e maio (início e meado do outono), julho (meado do inverno) e novembro (meado da primavera). As maiores frequências de elevadas médias do acumulado de chuva se deram em meses do outono, com maior média no mês de maio $(177,22 \mathrm{~mm})$. Já as menores médias acumuladas se deram em meses de fim de inverno e início de primavera, com a menor média no mês de setembro, com $84,47 \mathrm{~mm}$.

Para o período de 1996 a 2017, a série histórica permite observar, por meio da média do acumulado mensal, que o regime de chuvas do município considerado continuou bem distribuído ao longo dos meses, sendo que no fim do verão, no outono inteiro, e em meados da primavera estiveram os meses com maiores frequências elevadas de chuva. $\mathrm{O}$ mês que apresentou a maior média acumulada de precipitação foi novembro, com 201,095 mm; já o mês com a menor média acumulada foi setembro, com 77,54 mm.

No primeiro período, as normais climatológicas do município de Belmonte foram: janeiro $114,88 \mathrm{~mm}$, fevereiro $113,24 \mathrm{~mm}$, março $154,91 \mathrm{~mm}$, abril 166,06mm, maio $177,22 \mathrm{~mm}$, junho $143,88 \mathrm{~mm}$, julho $156,94 \mathrm{~mm}$, 
Figura 2. Localização do município de Belmonte e de Ipiaú no que se refere às Zonas Climáticas do IBGE, e às faixas de regime de distribuição de umidade, no estado da Bahia.

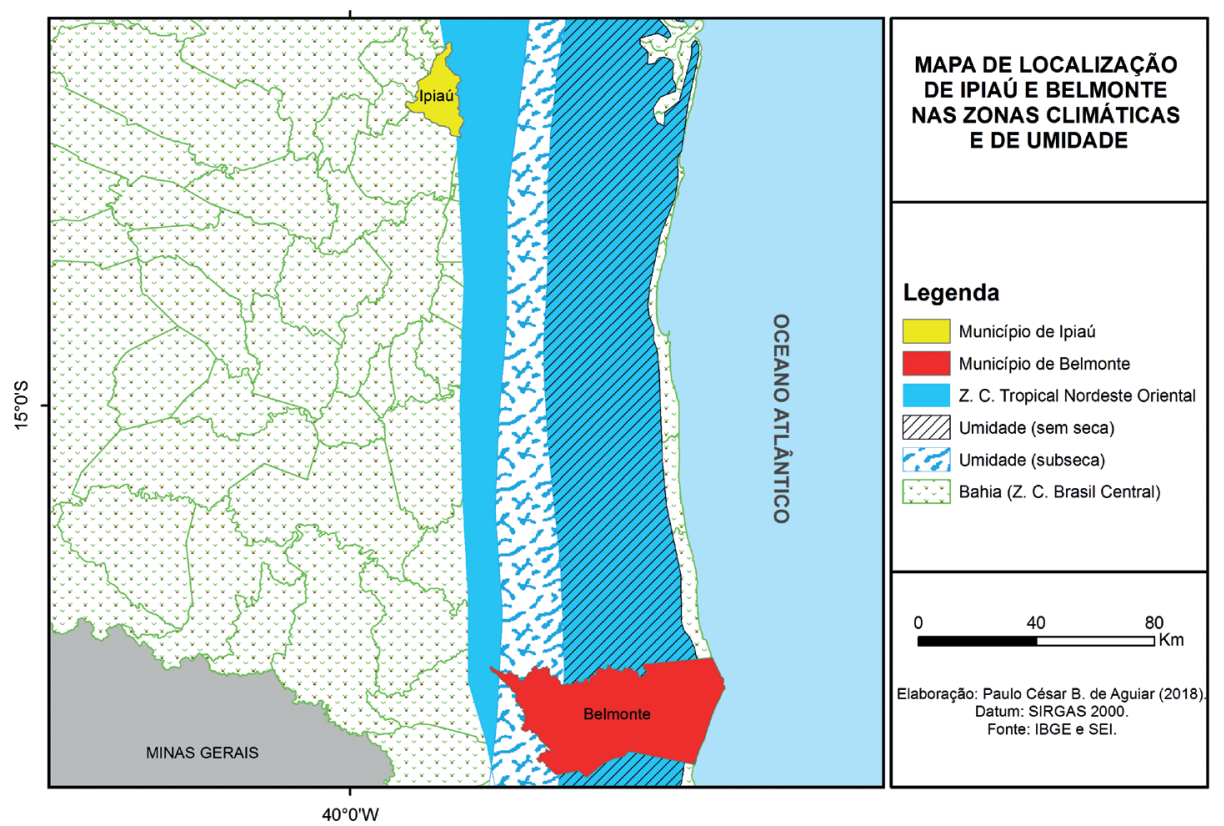

Elaboração própria: Aguiar, Paulo César B. de. a partir de bases cartográficas do IBGE e da SEI.

agosto $112,94 \mathrm{~mm}$, setembro $84,47 \mathrm{~mm}$, outubro $102,49 \mathrm{~mm}$, novembro $154,88 \mathrm{~mm}$, dezembro $109,12 \mathrm{~mm}$. Já para o segundo período, as normais climatológicas foram: janeiro $104,41 \mathrm{~mm}$, fevereiro $103,375 \mathrm{~mm}$, março $156,43 \mathrm{~mm}$, abril $172,98 \mathrm{~mm}$, maio $179,505 \mathrm{~mm}$, junho $181,64 \mathrm{~mm}$, julho $140,87 \mathrm{~mm}$, agosto $91,945 \mathrm{~mm}$, setembro $77,54 \mathrm{~mm}$, outubro $114,07 \mathrm{~mm}$, novembro $201,095 \mathrm{~mm}$, dezembro $143,055 \mathrm{~mm}$.

O comparativo entre as normais climatológicas do período 1956 a 1987 com o período 1996 a 2017 permite observar que, embora as médias de chuva nos dois períodos se apresentem bem distribuídas ao longo dos meses, no segundo período ocorre um aumento na média de chuva nos meses de março, abril, maio, junho, outubro, novembro e dezembro, se comparado aos mesmos meses do período anterior - o maior aumento na média acumulada se deu no mês de novembro, com 46,215mm a mais que o acumulado do mesmo mês do período anterior. Portanto, percebe-se que 
o aumento na média acumulada de chuva se deu nos meses que compreendem o fim do verão, todo o outono e quase toda a primavera (Figura 3).

Por outro lado, os meses de janeiro e fevereiro, julho, agosto e setembro apresentaram redução na média acumulada mensal de precipitação atmosférica (chuva) no segundo período se comparado com o primeiro, ou seja, em meados do verão e praticamente em quase todo o inverno - sendo que a menor média acumulada se deu no mês de setembro, com 77,54mm (Figura 3).

De forma geral, o segundo período apresentou um acréscimo de $75,885 \mathrm{~mm}$ na média acumulada de chuva no somatório dos meses, se comparado ao primeiro período. Possivelmente esse aumento geral na média total de precipitação no município podem estar ligados a fatores externos ao município, como aquecimento global, el niño, mudança climática, que são fatores que espraiam suas consequências para diferentes lugares e impactam o local em maior ou menor intensidade em função da localização e de aspectos fisiográficos; ou mesmo pode estar associado conjuntamente a fatores internos ao município.

Figura 3. Comparativo entre as normais climatológicas do município de Belmonte, do período 1956 a 1987, com a normal climatológica do período 1996 a 2017.

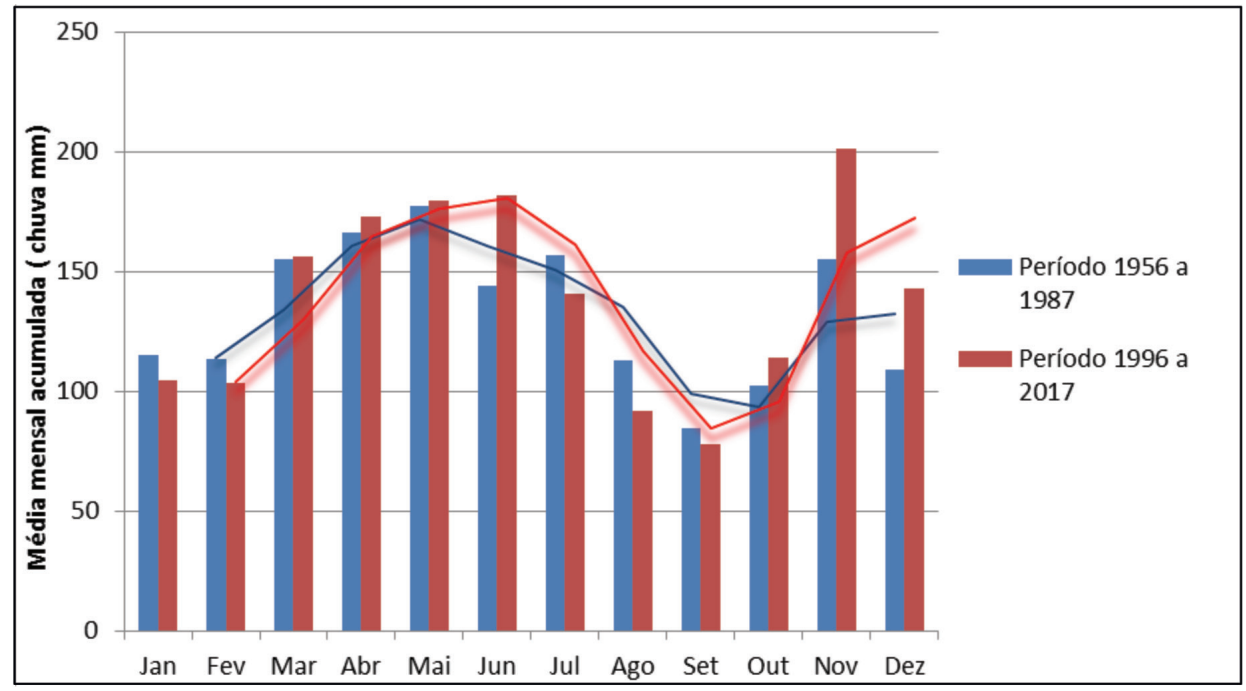

Fonte: Hidroweb (2018).

Elaboração própria: Aguiar, Paulo César B. de. 
Segundo Calasans, Levy e Moreau (2005), as precipitações podem variar tanto do ponto de vista geográfico quanto do aspecto sazonal, sendo que dentre os fatores que influenciam a precipitação estão a latitude (quanto mais próximo das baixas latitudes/próximo à linha do equador, maior é a incidência da radiação solar, de vegetação, de umidade, e, por consequência, de chuva); a distância do mar ou de outras fontes de água (quanto mais próximo de fontes de água maiores são as tendências de incidência de chuva por conta da forte evaporação, condensação e precipitação); altitude e orientação das encontas, que podem alterar a direção dos ventos ou podem antecipar a precipitação pluviométrica, por ser uma barreira à passagem de nuvens carregadas de chuva.

Estimativa de Nascimento e Dominguez (2010) aponta que originalmente o município de Belmonte teria sido coberto $100 \%$ por vegetação florestal típica da Mata Atlântica. Esse fato, associado à presença de extenso rio passando por seu território (Rio Jequitinhonha) e à localização geográfica desse município na faixa litorânea - fatores que estão entre os apontados por Calasans, Lévy e Moreau (2010) como favoráveis à boa incidência de precipitação - certamente contribuíram para a boa distribuição de chuva nesse município, sobretudo no primeiro período analisado.

Contudo, segundo Nascimento e Dominguez (2010), em anos recentes tem havido significativos desmatamentos no município de Belmonte, principalemente em áreas de tabuleiros costeiros, se concentrando ao lado da estrada BA-275 até a localidade de Cepá, e na parte central do município em direção oeste até a BR-101. Esse fato, pelos dados observados para o segundo período, não influenciou para um processo geral de redução de chuvas no município.

O desvio relativo para o total mensal de precipitação pluviométrica para o período de 1956 a 1987 aponta que, de forma geral, o período apresentou certa constância na tendência de precipitação, com alguns desvios nessa tendência ao apresentar certos picos mensais de chuva. O município de Belmonte, no referido período, apresentou uma anomalia de precipitação mensal no ano de 1960, dentro da concepção de anomalia apresentada por Angelocci e Sentellhas (2010), que seria uma flutuação grande de um elemento em uma série climatológica, ou seja, um desvio acentuado do padrão observado de variabilidade. No mês de março de 1960, os dados disponíveis apontam que o referido município apresentou um total mensal 
de chuva de 690,2mm, levando a um desvio relativo de 345,557 - destoando completamente da tendência observada (Figura 4).

Figura 4. Desvio relativo (total mensal) de chuva no município de Belmonte, no período de 1956 a 1987.

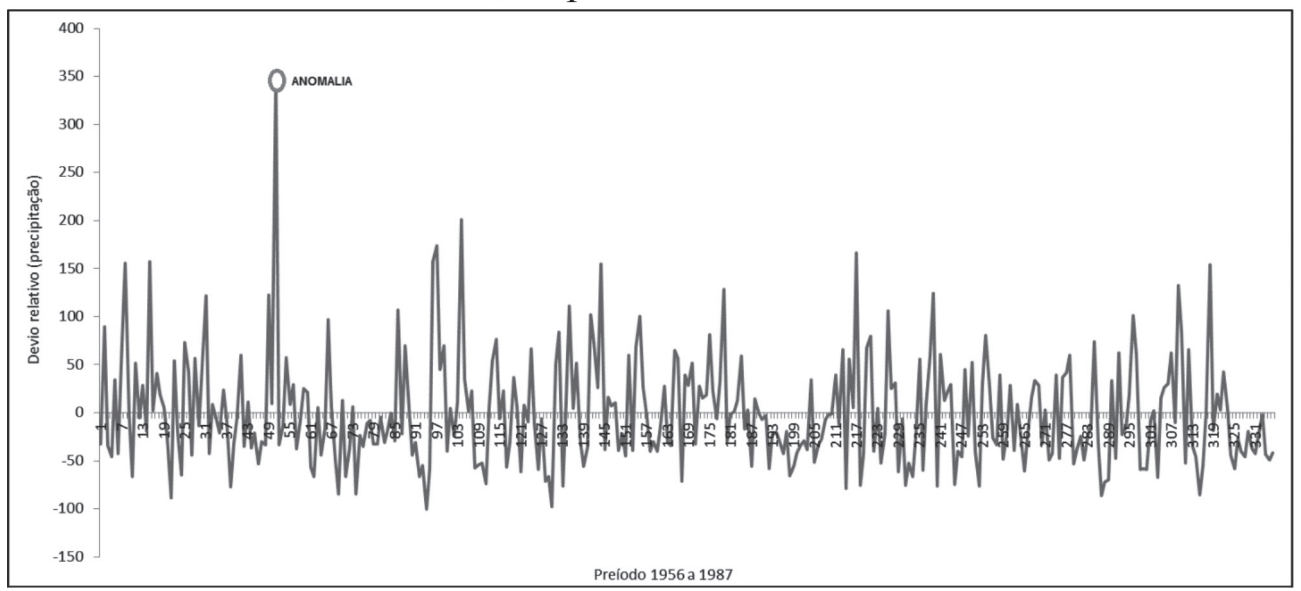

Fonte: Hidroweb (2018). Elaboração própria: Aguiar, Paulo César B. de.

Já no período de 1996 a 2017, o município de Belmonte apresentou cinco anomalias de precipitação pluviométrica. Essas anomalias se deram no ano de 1996, quando no mês de novembro choveu 518,8mm, dando um desvio relativo de 157,988 , e no mês de dezembro, quando choveu $521,3 \mathrm{~mm}$, dando um desvio relativo de 264,405; e no ano de 1998, quando no mês de março choveu $570,5 \mathrm{~mm}$, dando um desvio relativo de 264,670, no mês de maio, quando choveu $620,5 \mathrm{~mm}$, dando um desvio relativo de 245,673, e no mês de julho, quando choveu 504,6mm, dando um desvio relativo de 258,203 (Figura 5). Portanto, os dados relativos a esse segundo período apontam que no mesmo aconteceram meses com maiores extremos de picos de chuva, sobretudo nos primeiros anos. 
Figura 5. Desvio relativo (total mensal) de chuva no município de Belmonte, no período de 1996 a 2017.

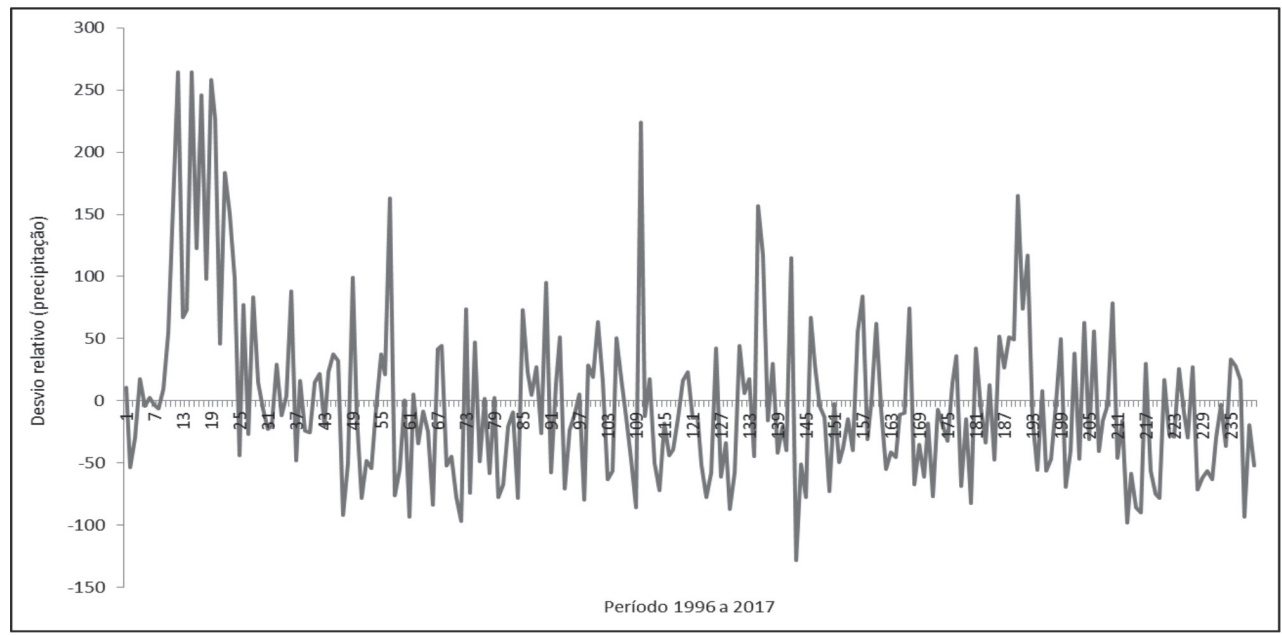

Fonte: Hidroweb (2018). Elaboração própria: Aguiar, Paulo César B. de.

Por sua vez, no que se refere ao município de Ipiaú, no período compreendido entre os anos de 1950 a 1979 (primeiro período analisado), as maiores médias do acumulado mensal de chuva apontam que as maiores incidências de precipitações pluviométricas se deram nos meses de novembro, dezembro, janeiro, março e abril; sendo que a maior média do acumulado mensal foi a do mês de dezembro, com 129,9mm. Os meses de fevereiro, junho, julho e outubro também apresentaram médias significativas, embora menores que as dos meses citados. As menores médias foram as dos meses de maio, agosto e setembro (sendo setembro a menor de todas, com 51,5mm).

Para o período de 1980 a 2008 (segundo período), os meses de dezembro, novembro e abril foram os meses que apresentaram as maiores médias mensais do acumulado de chuva, sendo o mês de dezembro aquele que apresentou a maior média, com 134,2mm; a partir do mês de maio a tendência foi de declínio das médias entre os meses subsequentes. $\mathrm{O}$ mês que apresentou a menor média do acumulado mensal foi setembro, com $54,1 \mathrm{~mm}$. Por estação do ano, as maiores médias de chuva foram as de fins de primavera, todo o verão e início do outono; já as menores médias foram as de inverno, início de primavera e fim do outono. 
O comparativo entre os dois períodos considerados (Figura 6), para Ipiaú, permite perceber que o primeiro período apresentou uma maior quantidade de meses com elevada média de chuva se comparado com o segundo período. No que se refere à média anual de chuva, o primeiro período apresentou uma média anual de $1.071,3 \mathrm{~mm}$; já o segundo período, uma média anual de $1.087,5 \mathrm{~mm}$. Portanto, a média anual do segundo período superou a do primeiro em $16,2 \mathrm{~mm}$.

Figura 6. Comparativo entre as normais climatológicas do município de Ipiaú do período 1950 a 1979, com a normal climatológica do período 1980 a 2008.

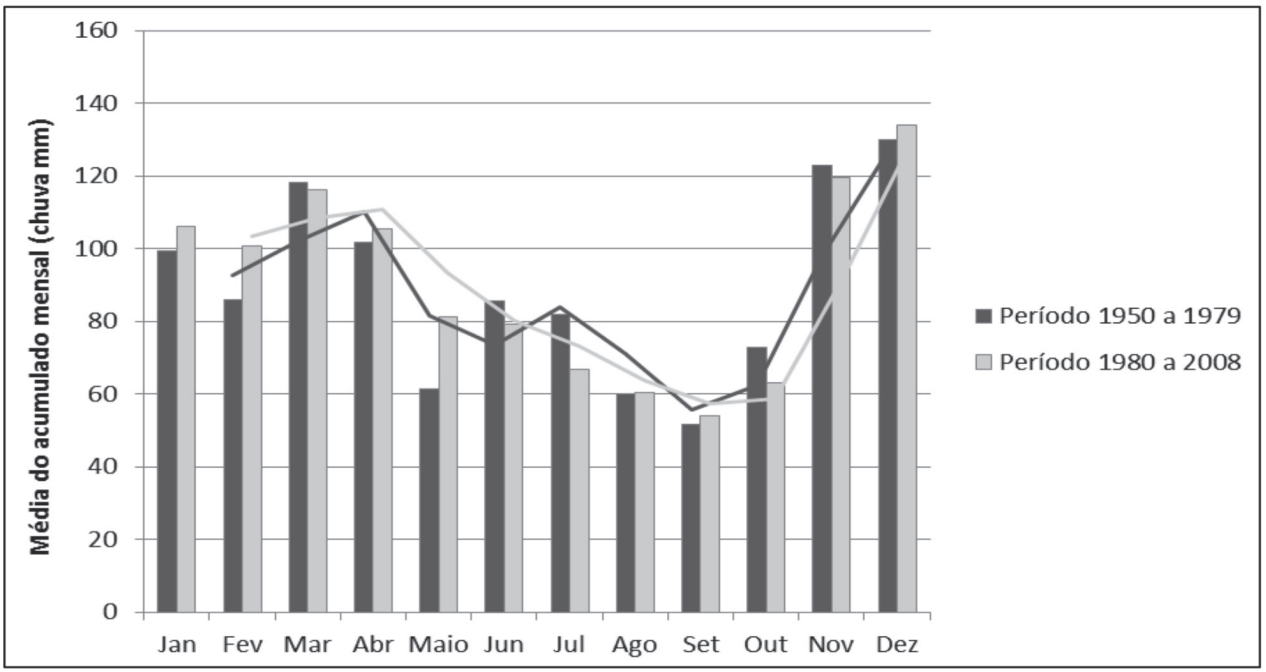

Fonte: Hidroweb (2018).

Elaboração própria: Aguiar, Paulo César B. de.

O desvio relativo para o total mensal de chuva em Ipiaú, relativo ao primeiro período, apontou que o perfil da tendência de distribuição de chuvas no período não apresentou significativas variações. Apenas um caso específico foge a essa regra, quando no mês de janeiro de 1964 choveu um total de $595,3 \mathrm{~mm}$, sendo que em apenas quatro dias do referido mês chegou a chover $300 \mathrm{~mm}$, ou seja, um elevado índice de chuva, bem superior à tendência (Figura 7). Nos demais meses ao longo de todo o período não se observou um total mensal de chuva que tenha ultrapassado os $300 \mathrm{~mm}$ (a 
exceção do mês de novembro de 1968, quando choveu um total de $386 \mathrm{~mm}$ ). O nível de chuva de 595,3mm observado em janeiro de 1964 se assemelha ao que Angelocci e Sentelhas (2010) chamam de anomalia climatológica, representando um desvio acentuado do padrão observado de variabilidade.

Figura 7. Desvio relativo da precipitação pluviométrica no município de Ipiaú, de 1950 a 1979.



Fonte: Hidroweb (2018).

Elaboração própria: Bruno, Nelma Lima

Para o segundo período, o desvio relativo permite observar que ocorreram maiores picos de chuva, deixando evidente uma maior frequência na ocorrência de desvios da tendência de precipitação pluviométrica mensal (Figura 8). No mês de fevereiro do ano de 1980 o total mensal de chuva correspondeu a $451 \mathrm{~mm}$, sendo que as precipitações ocorreram em 21 dias, no entanto, houve picos de chuva em três dias, perfazendo $300,6 \mathrm{~mm}$, sendo que o maior pico de chuva registrado em um único dia do referido mês foi de 123,8mm. Em janeiro do ano de 1985, o total mensal de chuva foi de $339,1 \mathrm{~mm}$, os quais se deram em 21 dias, sendo que os maiores picos se deram em três dias do referido mês perfazendo um total de $186,2 \mathrm{~mm}$, ou seja, mais da metade da chuva do mês, tendo o maior pico de um dia do referido mês $84 \mathrm{~mm}$. O maior pico de chuva em um mês se deu em dezembro 
de 1989 , com uma precipitação total de $511,8 \mathrm{~mm}$, embora com um perfil de chuva bem distribuído no mês. Já em janeiro de 2002 o total mensal registrado foi de $357,6 \mathrm{~mm}$, os quais se deram em 21 dias do mês, porém as maiores chuvas nesse mês se deram em quatro dias, perfazendo $214 \mathrm{~mm}$, ou seja, mais da metade do que choveu no mês inteiro.

Figura 8. Desvio relativo da precipitação pluviométrica no município de Ipiaú, de 1980 a 2008.

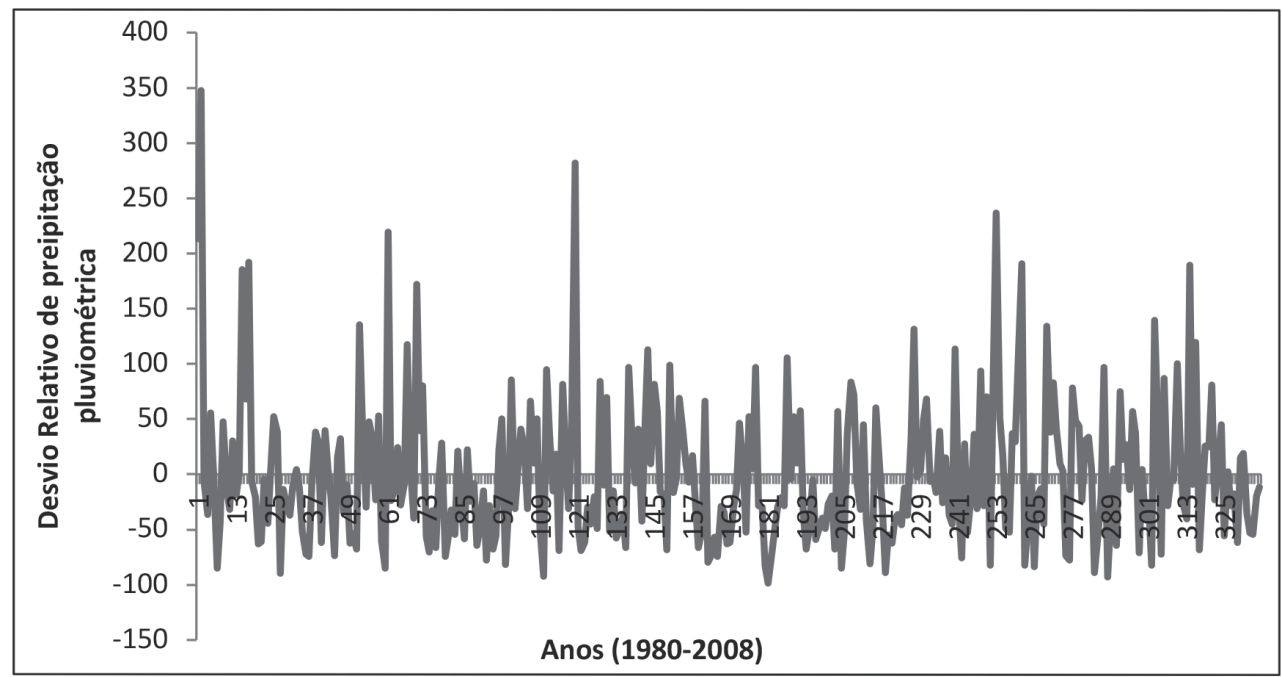

Fonte: Hidroweb (2018).

Elaboração própria: Bruno, Nelma Lima.

\section{Relação entre Precipitação Pluviométrica e Produção Agrícola nos Municípios}

O município de Belmonte, segundo o censo do IBGE de 2010, possuía uma população total de 21.798 habitantes (Tabela 2), com densidade demográfica de $11 \mathrm{hab} . / \mathrm{km}^{2}$, representando $2 \%$ da população da microrregião Ilhéus-Itabuna, que segundo o mesmo censo era de 1.020.642 habitantes. Da população total do município de Belmonte, 51,19\% eram pessoas do sexo masculino e $48,81 \%$ eram do sexo feminino, divergindo da realidade apontada pelo mesmo censo para o Estado da Bahia e para o Brasil, que possuíam, ambas as esferas, $51 \%$ da população sendo do sexo feminino contra $49 \%$ que era do sexo masculino. 
A maior parcela da população do referido município já se concentrava no espaço urbano (52,39\%), embora o percentual da população que se encontrava no espaço rural ainda fosse elevado $(47,61 \%)$ se comparado com a tendência dos principais municípios da microrregião Ilhéus-Itabuna, ou mesmo com a do estado da Bahia e a do Brasil, cuja taxa de urbanização era bem mais elevada.

Por sua vez, o município de Ipiaú, segundo o censo de 2010, possuía uma população total de 44.390 habitantes (Tabela 2), representando $4,4 \%$ da população da microrregião Ilhéus-Itabuna, constituindo-se na terceira maior população dessa microrregião, com densidade demográfica de 154,54 hab./ $\mathrm{km}^{2}$. Da população total do município de Ipiaú, $49,18 \% \%$ eram pessoas do sexo masculino e 50,82\% eram do sexo feminino, seguindo a mesma tendência apontada pelo mesmo censo para o estado da Bahia e para o Brasil.

O município de Ipiaú caracteriza-se por ser altamente urbanizado, sendo que, segundo o mencionado censo, $91 \%$ da população municipal se concentravam no espaço urbano, com apenas $9 \%$ da população vivendo em áreas rurais.

Portanto, enquanto para o município de Belmonte os dados percentuais apontam para uma grande parcela da população municipal vivendo no espaço rural, evidenciando que as atividades desenvolvidas no espaço rural são significativas para subsistência de boa parcela da população; por outro lado, o município de Ipiaú apresenta um percentual esmagador de sua população habitando o espaço urbano, evidenciando a predominância do setor de serviços na manutenção das famílias.

Tabela 2. População masculina e feminina residente, urbana, rural e total do município de Belmonte (Bahia), em 2010.

\begin{tabular}{|l|l|l|l|l|}
\hline \multirow{3}{*}{ SITUAÇÃO } & \multicolumn{2}{|c|}{$\begin{array}{c}\text { POPULCCÃO DO MUNICÍPIO DE } \\
\text { BELMONTE EM 2010 }\end{array}$} & $\begin{array}{c}\text { POPULAÇÃO DO MUNICÍPIO } \\
\text { DE IPIAÚ EM 2010 }\end{array}$ \\
\cline { 2 - 5 } & $\begin{array}{c}\text { FREQUÊNCIA } \\
\text { ABSOLUTA }\end{array}$ & $\begin{array}{c}\text { FREQUÊNCIA } \\
\text { PERCENTUAL }\end{array}$ & $\begin{array}{l}\text { FREQUÊNCIA } \\
\text { ABSOLUTA }\end{array}$ & $\begin{array}{c}\text { FREQUÊNCIA } \\
\text { PERCENTUAL }\end{array}$ \\
\hline MASCULINA & $11.159 \mathrm{hab}$. & $51,19 \%$ & $21.831 \mathrm{hab}$. & $49,18 \%$ \\
\hline FEMININA & $10.639 \mathrm{hab}$. & $48,81 \%$ & $22.559 \mathrm{hab}$. & $50,82 \%$ \\
\hline URBANA & $11.420 \mathrm{hab}$. & $52,39 \%$ & $40.395 \mathrm{hab}$. & $91 \%$ \\
\hline RURAL & $10.378 \mathrm{hab}$. & $47,61 \%$ & $3.995 \mathrm{hab}$. & $9 \%$ \\
\hline TOTAL & $\mathbf{2 1 . 7 9 8}$ hab. & $\mathbf{1 0 0 \%}$ & $\mathbf{4 4 . 3 9 0}$ hab. & $\mathbf{1 0 0 \%}$ \\
\hline
\end{tabular}

Fonte: PNUD - Atlas do Desenvolvimento Humano no Brasil, 2013.

Elaboração própria: aguiar, Paulo César B. de. 
O indicador Produto Interno Bruto Municipal (PIB-M), ao se constituir em um instrumento de mensuração, permite identificar a participação econômica municipal em três macrossetores de atividade (agropecuária, indústria e serviços), possibilitando ter-se certa noção da produção de riqueza e a distribuição da população economicamente ativa pelos setores de atividade.

No período compreendido entre os anos de 1999 a 2012, a maior representação percentual do PIB-M de Belmonte no PIB da microrregião Ilhéus-Itabuna foi no ano de 2012, com representação de 2,3\%, e a menor representação foi em 1999, com 1,2\%. Já em relação ao PIB da Bahia, a maior representação do PIB de Belmonte foi em 2012, com 0,14\%, e as menores representações foram nos anos 1999 e 2000, com 0,07\% nos dois anos (Tabela 3). Entre os anos de 1999 a 2012, o principal setor de atividade econômica no município de Belmonte foi o setor de serviços. A despeito disso, observa-se que no ano de 2012 o setor agropecuário representou $40,90 \%$ do PIB municipal - um percentual bem expressivo. Tal crescimento na participação do setor agropecuário coincide com o crescimento vertiginoso na produção de toras em madeira para papel e celulose no município, e do valor dessa atividade obtida - em 2011 a produção foi de 260.200 metros cúbicos e o valor obtido foi de R $\$ 12.268 .000,00$, e em 2012 a produção foi de $1.174 .585 \mathrm{~m}^{3}$ e o valor obtido foi de $\mathrm{R} \$ 87.554 .000,00$ (IBGE, 2015) - sendo que esse município é um dos grandes cultivadores desse produto, desenvolvido por empresa situada no Extremo Sul da Bahia. Além disso, o contingente de população rural desse município era significativo (conferir a tabela 2), o que implica em importância do setor agrícola para essa esfera da população. 


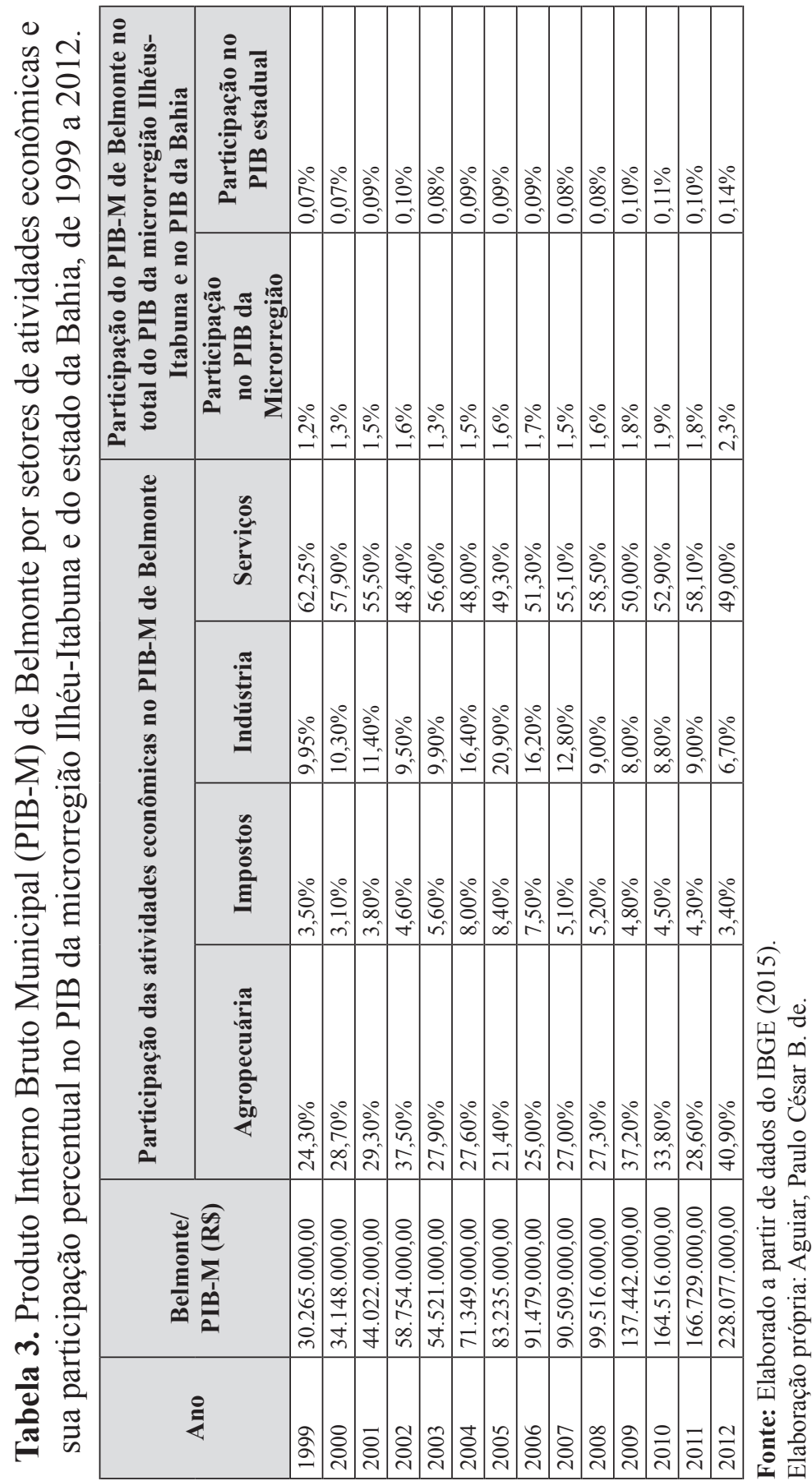


No período compreendido entre os anos de 1999 a 2012, o principal setor produtor de capital no município de Ipiaú foi o setor terciário (serviços), que de forma disparada correspondeu ao maior percentual da produção de receita no município e na concentração da maior parcela da população economicamente ativa que se encontrava ocupada em alguma atividade. $\mathrm{O}$ setor da indústria ocupou em todo o período (a exceção do ano de 2004) o segundo lugar na produção de recursos financeiros, atrás do setor de serviços, o que reforça a afirmativa do elevado nível de urbanização em que esse município já se encontrava e a posição de destaque do mesmo na microrregião, ocupando a terceira posição no âmbito socioeconômico, atrás apenas dos municípios de Itabuna e de Ilhéus - que são os centros polarizadores da microrregião (Aguiar, 2018; 2019). No mencionado período, percentualmente o PIB de Ipiaú teve pouca representação no PIB do estado da Bahia, variando entre a representação mínima de $0,16 \%$ (anos de 2005 a 2007) e a representação máxima de 0,22\% (ano de 2002).

Embora importante para o município, a agropecuária de Ipiaú representou em todo o período considerado (a exceção do ano de 2004) o menor percentual dentre os setores de atividade (Tabela 4). Na agricultura municipal, os produtos agrícolas que se destacaram em produção e valores da produção foram: abacaxi, amendoim em casca, banana, cacau (em amêndoa), cana-de-açúcar, coco-da-baía, goiaba, mandioca e maracujá; sendo que, de forma geral, o cacau foi aquele que mais se destacou na geração de divisas para o município. 
8

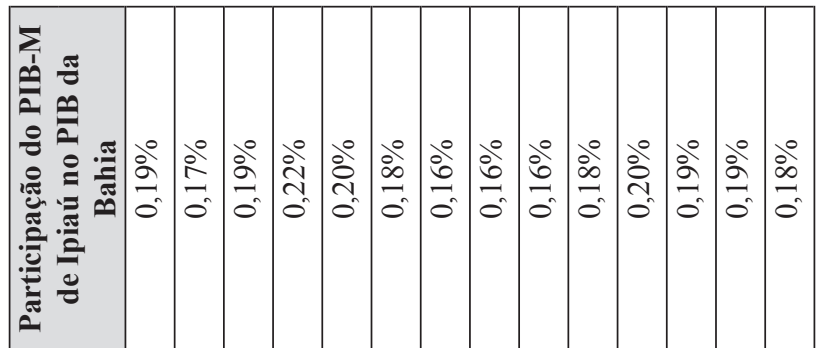

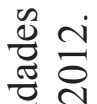

$\sum \pi$

范

ช

कृष्ठ

유.

总

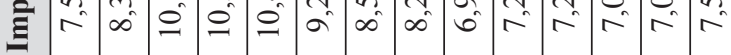

.尹

응

$\underset{8}{8}$

1'

光



.



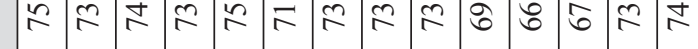


A ausência ou o excesso de chuva se constitui em um dos fatores limitantes ao dinamismo e à estabilização da produção agrícola, isso revela a importância de estudos em climatologia como instrumento de realizar planejamento das atividades agrícolas. No período chuvoso, as precipitações se caracterizam pela forte intensidade, e no período menos chuvoso, são frequentes as estiagens de duração variável, elevando o risco para as áreas agricultáveis (Moraes et al., 2005).

De acordo com Barbieri (2011), os choques climáticos afetam a disponibilidade de terras para cultivo e pecuária, o que afeta a capacidade produtiva e compromete a geração de renda e emprego. Dado o cenário climático A2 do Painel Intergovernamental sobre Mudanças Climáticas (IPCC) ${ }^{6}$, estudos da EMBRAPA indicam reduções significativas da oferta de terras aptas para a agricultura nos estados nordestinos. Espera-se, por exemplo, drástica redução de terras agricultáveis no Ceará $(-79,6 \%)$, no Piauí (-70,1\%), na Paraíba (-66,6\%) e em Pernambuco (-64,9\%). Ademais, estudos têm revelado que em ambientes rurais os pequenos e médios produtores familiares são os mais vulneráveis às oscilações climáticas extremas, especialmente as do gênero feminino. Além disso, tal problemática tem contribuído para a migração desses grupos para áreas periféricas das cidades, gerando mais pressões ambientais, as quais as políticas mitigadoras têm se mostrado insuficientes para minorar tais problemas (Kirsch; Schneider, 2016).

Para os grupos humanos que se encontram em condições socioeconômicas e ambientais mais susceptíveis de sofrer de forma mais profunda os impactos das mudanças climáticas, mesmo pequenas mudanças no clima podem ter impactos significativos sobre suas vidas e seus meios de subsistência. Pesquisas têm apontado que os danos provenientes da excessiva variação climatológica serão dificilmente suportados pelos agricultores de pequena escala, particularmente para os agricultores de países subdesenvolvidos e em vias de desenvolvimento (Machado Filho et al., 2016).

O município de Belmonte, conquanto tenha no setor de serviços o principal setor de atividades econômicas, também apresenta na agropecuária um forte setor de atividades, com significativa representação na composição do PIB (conferir tabela 3). Essa importância do setor agropecuário

6 O IPCC projetou cenários distintos para diferentes regiões da terra conforme os possíveis impactos/ consequências futuras advindas das mudanças climáticas em curso. 
pode estar diretamente influenciada por alguns fatores, como, por exemplo, o significativo percentual da população que ainda habita o espaço rural (conferir tabela 2), tendo nesse tipo de atividade a sua base de subsistência; os elevados e bem distribuídos índices de chuva no município, facilitado por sua localização geográfica em área litorânea em associação a relativa presença de vegetação de floresta típica da Mata Atlântica e a presença de um grande rio passando por seu território; e a ação de grande empresa explorando certo tipo de atividade típica desse setor; dentre outros fatores.

Por volta do ano de 1995 a cacauicultura ainda era a principal atividade agrícola do município de Belmonte, ocupando extensas áreas do seu território (Santos, 2008). Havia também extensas áreas do território municipal ocupadas por pastagens, significando supressão de áreas de floresta nativa por essa classe de uso do solo (Ib.). Segundo Santos (2008), desde 1973 as pastagens passaram a se constituir em elemento dominante na paisagem rural às margens da BR-101 e povoado de Santa Maria Eterna, e entre este e o povoado de Boca do Córrego (embora o município ainda apresentasse significativas áreas ocupadas por Floresta Ombrófila Densa), e ao longo da rodovia entre Santa Maria Eterna e o município de Canavieiras. A partir da década de 1980 esse processo de desmatamento tomou maior impulso no sentido norte do território de Belmonte, facilitado pela BR 101, a qual viabilizava o escoamento da madeira retirada dessas áreas. Santos (2008) acrescenta ainda que, as plantações de eucalipto iniciadas na década de 1990, vinham substituindo as áreas de pastagem, ocupando áreas planas dos tabuleiros, sem "ameaçar" as áreas com cacau. Porém, já no ano de 2005 havia um aumento significativo nas áreas ocupadas com o plantio de eucalipto, substituindo, em grande parte, áreas ocupadas com pastagens.

Segundo Nascimento; Dominguez e Silva (2009), gradativamente os tabuleiros costeiros dos municípios mais ao norte do Extremo Sul do Estado, como Belmonte, Eunápolis, Itabela, Itamaraju, Porto Seguro e Santa Cruz Cabrália, passaram a ser ocupados com cultivo de eucalipto. Esses autores mencionam que de 1990 para 2005, as áreas com eucalipto aumentaram nesse período 6,44 vezes (passando de 2.500 hectares para 18.600 hectares), favorecido pela implantação da unidade industrial da Veracel Celulose em uma área de $1.200 .000 \mathrm{~m}^{2}$, localizada entre os municípios de Eunápolis e Belmonte. Embora os plantios de eucalipto continuassem a crescer, as áreas destinadas ao plantio de cacau em Belmonte não se 
alteraram. Em 2005 é introduzido o plantio de mamão no município, o qual se avoluma, tornando-o presente no mosaico da paisagem do uso do solo desse território.

A partir de 2012 o setor agropecuário do município toma novo impulso, em função da produção de madeira em toras para fabricação de papel e celulose, o que contribuiu para aumentar a participação do setor agropecuário no PIB municipal (IBGE, 2015). Embora a microrregião Ilhéus-Itabuna, denominada de Região Cacaueira da Bahia, tenha se caracterizado historicamente como produtora de cacau, e a principal em nível de Brasil, na atualidade, o cacau já não representa o principal produto agrícola de muitos dos municípios que compõem essa região, embora ainda seja um dos três produtos agrícolas de relevância do município de Belmonte (Tabela 5).

Ao compararmos o perfil da produção de mamão, cacau, coco-da-baía e madeira em tora para produção de papel e celulose, com o perfil anual de chuva no município de Belmonte, para o período de 2004 a 2015 (Tabela 5), percebem-se poucos efeitos da alteração no perfil total de chuva no município sobre a produção. Isso pode ocorrer, porque, dentre outros fatores, mesmo nos anos de retração em sua pluviosidade total, percebe-se que a pluviosidade foi bem distribuída ao longo do ano, não gerando significativos prejuízos à dinâmica agrícola municipal.

Por sua vez, no município de Ipiaú, a agropecuária representa baixo percentual de participação na composição do PIB municipal, entre os setores da economia, ocupando a terceira posição entre os três setores da economia (serviços, indústria e agropecuária). Dentre os produtos da lavoura permanente, no período entre 2004 a 2014, os três principais produtos em produção e valor da produção foram: cacau, banana e maracujá (Tabela 6). O cacau, no período analisado, foi o produto agrícola que mais gerou divisas para o município, e em segunda e terceira posições destacaram-se a produção de banana e de maracujá.

Comparando-se o perfil da produção desses três principais produtos agrícolas com o perfil de precipitação pluviométrica no município de Ipiaú, no período de 2004 a 2014, pode-se observar que as variações entre os totais anuais de chuva, não influenciaram na produção (Tabela 6), dos mencionados produtos. 
Paulo César Bahia de Aguiar - Nelma Lima Bruno

Mônica de Moura Pires - Christiana Cabicieri Profice - Josiclêda Domiciano Galvíncio Effects of pluviometric precipitation on agricultural production in the municipalities of Belmonte and Ipiaú, Bahia states, Brazil

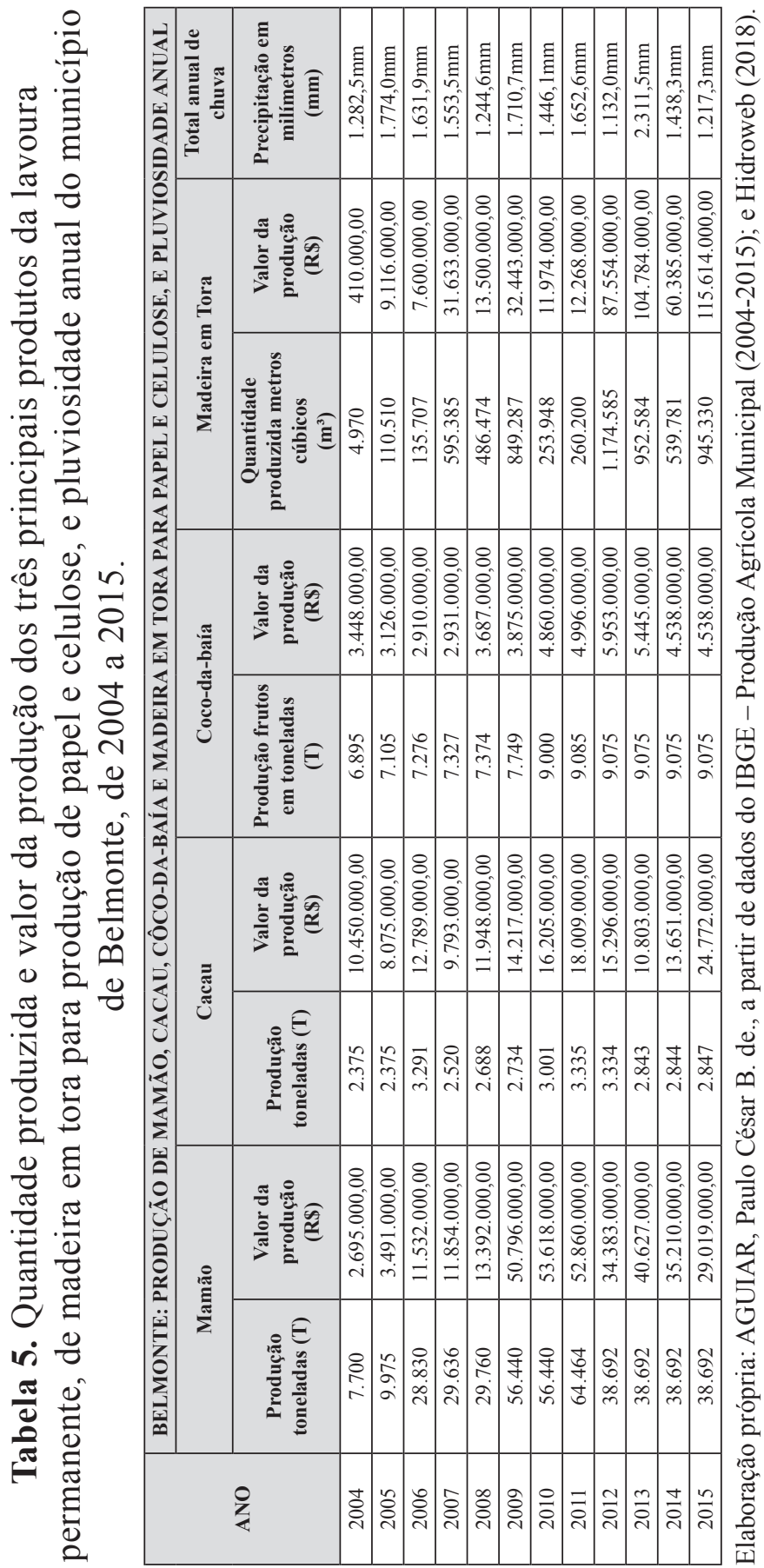


Bruno et al. (2016) e Bruno (2016), apontaram, que em anos de chuvas em excesso, sobretudo com picos concentrados em poucos meses, como o no ano de 2014 (novembro e dezembro), geram grandes perdas, especialmente nos cultivos de olerícolas, as quais são plantadas em áreas de brejo das zonas rurais do município de Ipiaú. Tal situação levou ao desabastecimento dos produtos no mercado local, e muitas vezes para atender aos clientes esses produtores adquiriam esses produtos em outras localidades.

Tabela 6. Quantidade produzida e valor da produção dos três principais produtos da lavoura permanente, e pluviosidade anual em milímetros (mm) do município de Ipiaú, Bahia, 2004 a 2014

\begin{tabular}{|c|c|c|c|c|c|c|c|}
\hline ANO & \multicolumn{2}{|c|}{ IPIAÚ: PRODUÇãO DE CACAU, BANANA E MARACUJA, E PLUVIOSIDADE ANUAL } \\
\hline & \multicolumn{2}{|c|}{ Cacau } & \multicolumn{2}{c|}{ Banana } & \multicolumn{2}{c|}{ Maracujá } & Chuva anual \\
\hline & $\begin{array}{c}\text { Produção } \\
\text { toneladas } \\
\text { (T) }\end{array}$ & $\begin{array}{c}\text { Valor da } \\
\text { produção } \\
\text { (R\$) }\end{array}$ & $\begin{array}{c}\text { Produção cacho } \\
\text { em toneladas } \\
\text { (T) }\end{array}$ & $\begin{array}{c}\text { Valor da } \\
\text { produção } \\
\text { (R\$) }\end{array}$ & $\begin{array}{c}\text { Produção em } \\
\text { toneladas (T) }\end{array}$ & $\begin{array}{c}\text { Valor da } \\
\text { produção } \\
\text { (R\$) }\end{array}$ & $\begin{array}{c}\text { Em milím. } \\
\text { (mm) }\end{array}$ \\
\hline 2004 & 4.187 & $22.903 .000,00$ & 9.000 & $2.250 .000,00$ & 36 & $18.000,00$ & 1.195 \\
\hline 2005 & 2.200 & $7.333 .000,00$ & 9.000 & $2.250 .000,00$ & 120 & $60.000,00$ & 1.036 \\
\hline 2006 & 2.200 & $7.810 .000,00$ & 10.500 & $3.255 .000,00$ & 84 & $42.000,00$ & 1.216 \\
\hline 2007 & 2.298 & $8.999 .000,00$ & 6.600 & $3.696 .000,00$ & 120 & $62.000,00$ & 1.417 \\
\hline 2008 & 2.185 & $8.085 .000,00$ & 7.250 & $4.459 .000,00$ & 84 & $51.000,00$ & 828,8 \\
\hline 2009 & 2.190 & $10.757 .000,00$ & 7.975 & $5.981 .000,00$ & 150 & $135.000,00$ & 725,2 \\
\hline 2010 & 2.190 & $10.757 .000,00$ & 7.975 & $5.981 .000,00$ & 150 & $135.000,00$ & 1.161 \\
\hline 2011 & 2.295 & $12.393 .000,00$ & 8.625 & $8.193 .000,00$ & 216 & $211.000,00$ & 1.227 \\
\hline 2012 & 2.508 & $12.841 .000,00$ & 9.000 & $7.470 .000,00$ & 180 & $183.000,00$ & 788 \\
\hline 2013 & 2.215 & $11.341 .000,00$ & 9.000 & $7.308 .000,00$ & 180 & $183.000,00$ & 880 \\
\hline 2014 & 3.980 & $23.482 .000,00$ & 160 & $128.000,00$ & 18 & $18.000,00$ & 911 \\
\hline
\end{tabular}

Elaboração: AGUIAR, Paulo César B. de., a partir de dados do IBGE - Produção Agrícola Municipal (2004-2014); INMET (2015); Hidroweb (2018).

\section{Considerações Finais}

A análise dos resultados obtidos com a pesquisa permite perceber um conjunto de situações distintas entre os dois municípios considerados (Belmonte e Ipiaú), evidenciado nas variações do padrão de precipitação nos períodos estudados, explicitando a realidade dessas precipitações e auxiliando na previsão da tendência futura das mesmas e os principais fatores que poderão influenciar esse processo.

Os dois municípios, conquanto situem-se em uma mesma microrregião, sofrem efeitos distintos dos padrões de chuva por diferentes fatores, dentre os quais estão a localização geográfica específica de cada um, tipos 
de solos característicos, maior ou menor extensão de remanescentes florestais no território, topografia, maior ou menor sensibilidade dos tipos de cultivos aos padrões de chuva, dentre outros fatores. Por exemplo, em Ipiaú há uma maior significância de cultivos temporários e mais sensíveis à intensidade de chuva (que nos últimos anos sofreu maiores desvios no padrão de precipitação se comparado a Belmonte), enquanto em Belmonte os cultivos tem maior significância entre os permanentes, o que pode resultar em maior intensidade para absorver os efeitos de chuvas muito severas.

Os resultados da pesquisa sinalizaram, por meio do comparativo entre as normais climatológicas do período 1956 a 1987 com o período 1996 a 2017, que os níveis de chuva no município de Belmonte foram bons e bem distribuídos nos dois períodos, sendo que o segundo período apresentou um acréscimo de $75,885 \mathrm{~mm}$ na média do acumulado de chuva no somatório dos meses, se comparado ao primeiro período. O primeiro período apresentou certa constância na tendência de precipitação, com alguns desvios nessa tendência ao apresentar certos picos mensais de chuva. Houve no segundo período a ocorrência de meses com maiores extremos de picos de precipitação pluviométricas. No entanto, nos últimos anos analisados, tanto os grandes níveis de chuva quanto a sua retração não levaram a uma redução na produção dos principais produtos agrícolas do município, sobretudo porque os bons índices de chuva e a sua boa distribuição foi o que ocorreu.

Por sua vez, para o município de Ipiaú, a partir do discutido ao longo do trabalho, pode-se concluir que, por meio da comparação entre as médias mensais acumuladas dos meses nos diferentes anos analisados, no primeiro período (1950-1979), houve uma melhor distribuição de chuva ao longo dos anos, e que o gráfico de desvio relativo apontou dentro do período que houve um mês dentro de um ano específico que apresentou uma excessiva precipitação pluviométrica, podendo ser associada a uma anomalia climatológica, dentro de definição presente na literatura arrolada no trabalho. Já no segundo período, os resultados indicaram que os índices de chuva foram significativos nos diferentes meses, porém concentrados sazonalmente; tais resultados foram observados no gráfico de desvio relativo, onde ocorreram mais picos de chuva em mais de um mês dos diferentes anos considerados. 
As tendências sinalizaram que em decorrência de algumas variabilidades climáticas possivelmente esta tenha contribuído para influenciar na agricultura do município e que tal variabilidade possivelmente possa estar associada a dinâmica natural ou consequências provenientes de ações antrópicas.

\section{Referências}

Aguiar, P. C. B. de. (2018). "Breve panorama econômico e socioterritorial recente da região Cacaueira do Sul do Estado da Bahia, Brasil." Investigaciones Geográficas, Chile, (55), 127-146. doi: 10.5354/0719-5370.2018.45195.

Aguiar, P. C. B. de. y Pires, M. M. (2019). “A região cacaueira do sul do estado da Bahia, Brasil: crise e transformacao." Cuadernos de Geografia: Revista Colombiana de Geografia, 28 (1): 192-208. doi: 10.15446/rcdg.v28n1.67437.

Angelocci, L. R. y Sentelhas, P. C. (2010). Variabilidade, Tendência, Anomalia e Mudança Climática. Material didático para uso exclusivo na disciplina LCE 306 - Meteorologia Agrícola Departamento de Engenharia de Biossistemas - setor de Agrometeorologia - ESALQ/USP.

Barbieri, A. F. (2011). "Mudanças Climáticas, Mobilidade Populacional e Cenários de Vulnerabilidade para o Brasil”. Revista Internacional de Mobilidade Humana, XIX (36), Brasília, 95-112.

Bruno, N. L. (2016). Nivel de Sustentabilidade Ambiental da Comunidade Rural Fazenda do Povo no Município de Ipiaú - Estado da Bahia, Brasil. 179 f. Dissertação (Mestrado em Desenvolvimento Regional e Meio Ambiente). Universidade Estadual de Santa Cruz. Ilhéus (BA): UESC. Bruno, N. L., Aguiar, P. C. B. de., Costa, L. C. B. y Sampaio, L. A. G. (2016). "Estratégia para o Desenvolvimento Rural Sustentável no Assentamento Coroa Verde, Barra do Rocha, Bahia (Brasil), através de uma Unidade Demonstrativo-Educativa". Revista Cientifica Monfragüe: Desarrollo Resiliente, VI (2), Espanha, 21-52. ISSN: $2340-5457$.

Calasans, N. A. R., Levy, M. C. T. y Moreau, M. (2005). "Interrelações Entre Clima e Vazão”. In: Schiavetti, A.; Camargo, A. F. M. (Org.). CONCEITOS DE BACIAS HIDROGRÁFICAS: Teorias e Aplicações. Ilhéus, Ba: Editus, pp. 67-90. 
Conti, J. B. (2005). "Considerações sobre as Mudanças Climáticas Globais". Revista do Departamento de Geografia, 16, 70-75.

Gouveia, R. L., Paz, Y. M., Galvíncio, J. D. y Souza, W. M. (2017). "Mudanças Climáticas e os Refugiados Ambientais”. In: Galvíncio, J. D., Oliveira, V. S. y Souza, W. M. (Org.). Mudança Climática, Sociedade e Meio Ambiente. Recife: Editora da UFPE, pp. 41-77.

HIDROWEB - Sistema de Informações Hidrológicas. (2018). Medições históricas de precipitações pluviométricas do município de Belmonte, de 1956 a 1987, e de 1996 a 2017. <http://www.snirh.gov.br/hidroweb/publico/medicoes_historicas_abas.jsf $>$.

HIDROWEB - Sistema de Informações Hidrológicas. (2018). Medições históricas de precipitações pluviométricas do município de Ipiaú, de 1950 a 1979, e de 1980 a 2008. <http://www.snirh.gov.br/hidroweb/ publico/medicoes_historicas_abas.jsf $>$.

IBGE - Instituto Brasileiro de Geografia e Estatística. (2010). Censo 2010.

População do município de Belmonte. Rio de Janeiro: IBGE.

IBGE - Instituto Brasileiro de Geografia e Estatística. (2010). Censo 2010.

População do município de Ipiaú. Rio de Janeiro: IBGE.

IBGE - Instituto Brasileiro de Geografia E Estatística. (2010). População brasileira. Censo 2010. Rio de Janeiro: IBGE.

IBGE - Instituto Brasileiro de Geografia e Estatística. (2015). Produto Interno Bruto do Município de Belmonte, de 1999 a 2012. Rio de Janeiro: IBGE. <http://www.deepask.com/goes?page=belmonte/ BA-Confira-o-PIB---Produto-Interno-Bruto---no-seu-municipio>.

IBGE - Instituto Brasileiro de Geografia e Estatística. (2015). Produ-

to Interno Bruto do Município de Ipiaú, de 1999 a 2012. Rio de Janeiro: IBGE. <http://www.deepask.com/goes?page=ipiau/ BA-Confira-o-PIB---Produto-Interno-Bruto---no-seu-municipio $>$.

IBGE - Instituto Brasileiro de Geografia e Estatística. (2014). Produção Agrícola Municipal de Ipiaú, de 2004 a 2014. Rio de Janeiro: IBGE. <https://cidades.ibge.gov.br/brasil/ba/belmonte/ pesquisa/15/11863?ano $=2014>$.

IBGE - Instituto Brasileiro de Geografia e Estatística. (2015). Produção Agrícola Municipal de Belmonte, de 2004 a 2015. Rio de Janeiro: IBGE. <https://cidades.ibge.gov.br/brasil/ba/belmonte/ pesquisa/15/11863?ano=2015>. 
IBGE - Instituto Brasileiro de Geografia E Estatística. (2017). Divisão regional do Brasil em regiões geográficas imediatas e regiões geográficas intermediárias. Rio de Janeiro: IBGE.

INMET - Instituto Nacional de Meteorologia. (2015). Índice Pluviométrico do município de Ipiaú, de 2009 a 2014. <www.inmet.gov.br/ portal/index.php?r=home\&page=rede_estacoes_auto_graf $>$.

IPCC - Intergovernmental Panel in Climate Change. (2007). Climate Change 2007: The Physical Science Basis. Summary for Policymakers. < http:/www.ipcc.ch/SPM2dez07.pdf>.

Kirsch, H. M. y Schneider, S. (2016). "Vulnerabilidade Social às Mudanças Climáticas em Contextos Rurais". Revista Brasileira de Ciências Sociais, 31 (91), 1-15.

Machado Filho, H. (2016). "Mudança do clima e os impactos na agricultura familiar no Norte e Nordeste do Brasil". Centro Internacional de Políticas para o Crescimento Inclusivo. Programa das Nações Unidas para o Desenvolvimento. SBS, Quadra 1, Bloco J, Ed. BNDES, $13^{\circ}$ andar, 70076-900 Brasília, DF - Brasil.

Moraes, B. C., Costa, J. M. N., Costa, A. C. L. y Costa, M. H. (2005). "Variação espacial e temporal da precipitação no estado do Pará". Acta Amazônica, 35(2), 207 - 214.

Nascimento, D. M. C., Dominguez, J. M. L. y Silva, S. B. de M. e. (2009). "Mudanças na Ocupação Econômica do Litoral Sul da Bahia: Os exemplos de Belmonte e Canavieiras". Revista Desenbahia, n ${ }^{\circ} 10 .<\mathrm{http}: / /$ www.desenbahia.ba.gov.br/recursos/news/video/\%7BC7562424-BA33-49D4-9F6C-809EB0E48507\%7D_Rev10_Cap1.pdf>.

Nascimento, D. M. C. y Dominguez, J. M. L. (2010). "Remanescentes da cobertura Vegetal: Uma contribuição cartográfica à gestão ambiental na zona costeira dos municípios de Belmonte e Canavieiras na Bahia, Brasil”. Cadernos de Geociências, 7 (2).

Oliveira, M. J. de. y Vecchia, F. (2011). "Normais climatológicas no contexto das mudanças climáticas: Análise dos casos de São Paulo/SP e Franca/SP". Centro de Recursos Hídricos e Ecologia Aplicada, Departamento de Hidráulica e Saneamento, Escola de Engenharia de São Carlos, Universidade de São Paulo. 
Piao, S., Ciais, P., Huang, Y., Shen, Z., Peng, Shushi P., Li, J., Zhou, L., Liu, H., Ma, Y., Ding, Y., Friedlingstein, P., Liu, C., Tan, K., Yu, Y., Zhang, T. y Fang, J. (2010). "The impacts of climate change on water resources and agriculture in China". Nature, 467, 43-51. doi: 10.1038/nature09364.

PNUD - Programa das Nações Unidas para o Desenvolvimento. Atlas do Desenvolvimento Humano no Brasil. (2013). Indicador Habitação. Variáveis "percentual da população em domicílios com água encanada, com coleta de lixo, e com energia elétrica", nos municípios de Belmonte e de Ipiaú, em 2010.<http://atlasbrasil.org.br/2013/>.

PNUD - Programa das Nações Unidas para o Desenvolvimento. Atlas do Desenvolvimento Humano no Brasil. (2013). Índice de Desenvolvimento Humano dos municípios de Belmonte e de Ipiaú, em 2010.< http://atlasbrasil.org.br/2013/>.

PNUD - Programa das Nações Unidas para o Desenvolvimento. Atlas do Desenvolvimento Humano no Brasil. (2013). População feminina e masculina, e rural, urbana e total, dos municipios de Belmonte e de Ipiaú, em 2010.<http://atlasbrasil.org.br/2013/>.

Salamanca, A. E., Sierra, R. D., Aranda, R. M. M, y Santos, M. J. (2017). "Environmental impacts of climate change adaptation". Environmental Impact Assessment Review, 64, 87-96.

Santos, A. P. (2008). Apropriação da Natureza e Produção do Espaço no Município de Belmonte - Bahia. 146f. Dissertação (Mestrado em Geografia). Universidade Federal da Bahia. Instituto de Geociências. Salvador: UFBA.

Santos, A. S. (2018). Vulnerabilidades socioambientais diante das mudanças climáticas projetadas para o semiárido da Bahia. Dissertação - Mestrado em Desenvolvimento Sustentável. Universidade de Brasília: Centro de Desenvolvimento Sustentável. 153f.

SEI. Superintendência de Estudos Econômicos e Sociais da Bahia. (1998). Análise dos atributos climáticos do Estado da Bahia. Salvador. B.. 85 p. (Série Estudos e Pesquisas, 38).

Souza, W. M.; Azevedo, P. V. (2012). "Índices de Detecção de Mudanças Climáticas Derivados da Precipitação Pluviométrica e das Temperaturas em Recife-PE". Revista Brasileira de Geografia Física, 01, 143-159. 
